Revista Aspas

ppgac - USP

Especial

\title{
ESSE CORPO QUE ME VESTE: O TRAJE DE CENA COMO DISPARADOR DE UMA PESQUISA ACADÊMICA
}

THE BODY THAT DRESSES ME: THE COSTUME AS A TRIGGER OF AN ACADEMIC RESEARCH

\section{ESE CUERPO QUE ME VISTE: EL VESTUARIO ESCÉNICO COMO} DETONANTE DE UNA INVESTIGACIÓN ACADÉMICA

\section{Graziela Ribeiro Baena}

Graziela Ribeiro Baena

Mestra e Doutora pelo Programa de Pós-graduação em Artes da

Universidade Federal do Pará na linha Teorias e Interfaces Epistêmicas em Artes. Foi orientada pela Profa Dra Wladilene de

Sousa Lima e foi bolsista da CAPES no ano de 2018. Atua profissionalmente como figurinista e maquiadora de teatro e audiovisual na cidade de Belém do Pará. 


\begin{abstract}
Resumo
O artigo aborda uma pesquisa teórica sobre a indumentária da festividade religiosa amazônica do culto ao São Benedito de Bragança (PA), que teve como disparador a construção do traje de cena do espetáculo teatral "Esse corpo que me veste", realizado pelo grupo Cuíra e apresentado em 2015, em Belém do Pará.
\end{abstract}

Palavras-chave: Amazônia, Belém, Cuíra, figurino, teatro

\title{
Abstract
}

The article is about a theoretical research on the costume of the Amazonian religious celebration of Saint Benedict of Bragança (PA), which was the trigger to the construction of the stage costume of the theatrical spectacle "Esse corpo que me veste", performed by the Cuíra group and presented in 2015, in Belém do Pará.

Keywords: Amazon, Belém, Cuíra, costume, theater.

\section{Resumen}

El artículo aborda una investigación teórica sobre el atuendo de la fiesta religiosa amazónica del culto a San Benedito de Bragança (PA), que tuvo como detonante la construcción del vestuario escénico del espectáculo teatral "Esse corpo que me veste", realizado por el grupo Cuíra y presentado en 2015, en Belém de Pará.

Palabras clave: Amazonia, Belém, Cuíra, vestuario, teatro.

\section{Introdução}

Este artigo é composto por um fragmento da pesquisa de doutorado, iniciada em 2016 e concluída em 2020, que foi desenvolvida dentro do Programa de Pós-Graduação em Artes da Universidade Federal do Pará, intitulada "Entre marujas e marujos: recortes sobre o vestir no culto a São Benedito em Bragança (PA)".

Embora o trabalho completo tenha tratado dos trajes usados pelos devotos em diversos momentos da festividade acima mencionada, incluindose neste contexto os paramentos e adereços, nesta escrita serão 
apresentadas maiores informações sobre o chapéu de maruja, tendo em vista que este objeto foi a inspiração para o figurino do espetáculo "Esse corpo que me veste".

O estudo do chapéu se deu por meio de dois caminhos: o primeiro deles foi um levantamento teórico em livros, dissertações e artigos sobre a Marujada, e o outro foi por meio de entrevistas com participantes da festividade, principalmente com a artesã bragantina Teresa O'Grady, que confecciona chapéus.

Assim, neste artigo traremos alguns dados referentes à pesquisa teórica realizada acerca deste adereço tão marcante na visualidade da festividade. Os dados apresentados neste trabalho foram obtidos através de uma metodologia de pesquisa conhecida como Etnometodologia. Uma das noções da etnometodogia diz respeito ao método documentário de análise que, resumidamente, tenta traçar o passado de um fenômeno social, para que assim se compreenda o presente. Deste modo o artigo se organiza da seguinte forma: primeiramente temos esclarecimentos sobre o espetáculo mencionado como iniciador da pesquisa teórica, em seguida, foi inserido o estudo sobre os chapéus usados como inspiração no figurino do espetáculo; finalmente, temos a conclusão do estudo.

\section{Para a compreensão do espetáculo "Esse corpo que me veste"}

Com a finalidade de contextualizar a narrativa deste artigo, é importante primeiramente apresentar o espetáculo "Esse corpo que me veste". Trata-se de uma obra teatral realizada em 2015, resultado de uma investigação sobre teatro litúrgico contemporâneo desenvolvida pela Prof ${ }^{a}$. Dr ${ }^{a}$. Olinda Charone que, resumidamente, costura "histórias de várias pessoas e a sua relação com a religiosidade, sem se prender a uma religião específica"'. Tendo como foco as religiões que se fazem presentes na Amazônia brasileira, a

\footnotetext{
${ }^{1}$ Fonte: http://fcp.pa.gov.br/noticias/1489-esse-corpo-que-me-veste-sera-exibido-nesta-segundafeira-no-cine-alexandrino-moreira
} 
experimentação cênica foi montada por meio da premiação da Fundação Cultural do Pará.

Para fins complementares, cabe ressaltar a ficha técnica do espetáculo: a pesquisa foi realizada por Olinda Charone e convertida em dramaturgia por Edyr Augusto. A direção foi de Wlad Lima e o elenco composto por Zê e Olinda Charone, João Pedro e D. Lucila, os dois últimos nomes são também membros da família das atrizes. A visualidade e iluminação foram criadas por Patrícia Gondim, com assistência de Bolyvar Junior e Ariane Gondim. A sonoplastia foi feita por Leoci Medeiros e o figurino ficou sob responsabilidade de Grazi Ribeiro.

Trazendo em sua dramaturgia a costura de relatos de fé de pessoas de diferentes crenças, o conteúdo da montagem apropriou-se de discursos advindos do catolicismo, das religiosidades afro-brasileiras, de práticas que fazem alusão a rituais de Seicho-no-ie e do Santo Daime, reforça-se assim o hibridismo presente na cultura brasileira e, sobretudo, na cultura amazônica. Estas múltiplas referências se materializaram na visualidade do espetáculo, incluindo-se aí o traje de cena e a cenografia.

Concebidas pela cenógrafa Patrícia Gondim, iluminação e cenografia ocuparam a sala da casa-teatro Cuíra, um casarão antigo no bairro histórico conhecido como Cidade Velha, localizado na cidade de Belém. A configuração espacial era simples, porém trouxe um aspecto intrigante, havia quadros nas paredes, que emolduravam imagens de entidades de várias religiões, de santos católicos ao Buda, uma forma de ilustrar a presença das mais diversas crenças religiosas mencionadas na encenação.

As duas atrizes em cena, as irmãs Zê e Olinda Charone usavam um figurino que também materializava referências do hibridismo religioso, muitas vezes apresentadas por camadas de roupas e adereços. Um exemplo disso foi o modelo de calça usado em algumas cenas pelas atrizes, que teve como inspiração o fato delas serem realmente irmãs e por isso vestindo uma apropriação das calças usadas em imagens de São Cosme e São Damião. Os detalhes de modelagem das roupas carregavam simbolismos relacionados ao tema, por exemplo, o traje da atriz Zê Charone era composto por uma camisa com gola padre, uma saia branca "de missa", por baixo da saia era 
usada a calça São Cosme e Damião. Havia também uma saia de aviamentos multicoloridos: botões, sutaches, guizos, fitas, sianinhas, simbolizando aviamentos usados em altares, trajes de São João e outras festas do catolicismo popular.

A atriz Olinda Charone usava a calça já mencionada, uma túnica branca e por cima um manto dourado com uma textura de flores de pena de pato. O objeto foi confeccionado com materiais que são usados em um enigmático chapéu, que é utilizado em uma das maiores festividades religiosas da Amazônia paraense: a Marujada bragantina. A Festividade do Glorioso São Benedito de Bragança, tradicionalmente homenageia o santo há mais de duzentos anos, no município de Bragança (PA). Este chapéu, que é usado pelas marujas, é composto por, além das flores de pena de patos, tecido dourado, enfeites e aviamentos como miçangas, paetês, pedrarias, isopor e fitas multicoloridas.

Aqui, escrevendo como autora deste artigo e como responsável pelo figurino supramencionado, posso afirmar que o ato de criação nesse trabalho não encerrou com sua apresentação, pois ele marcou o início de uma trajetória de pesquisa de quatro anos, que buscou preencher lacunas deixadas pela pesquisa criativa, principalmente no que concerne ao chapéu das marujas.

\section{Investigações teóricas sobre os chapéus das marujas}

Embora o figurino do espetáculo tratado neste artigo tenha inspiração nos chapéus das marujas de São Benedito, este tópico inclui uma breve explanação a respeito dos chapéus masculinos também. Estes chapéus compõem a indumentária dos participantes da festividade, que é composta também por roupas e outros acessórios, conforme verifica-se na imagem a seguir: 
Fig. 1 - Chapéus de maruja.

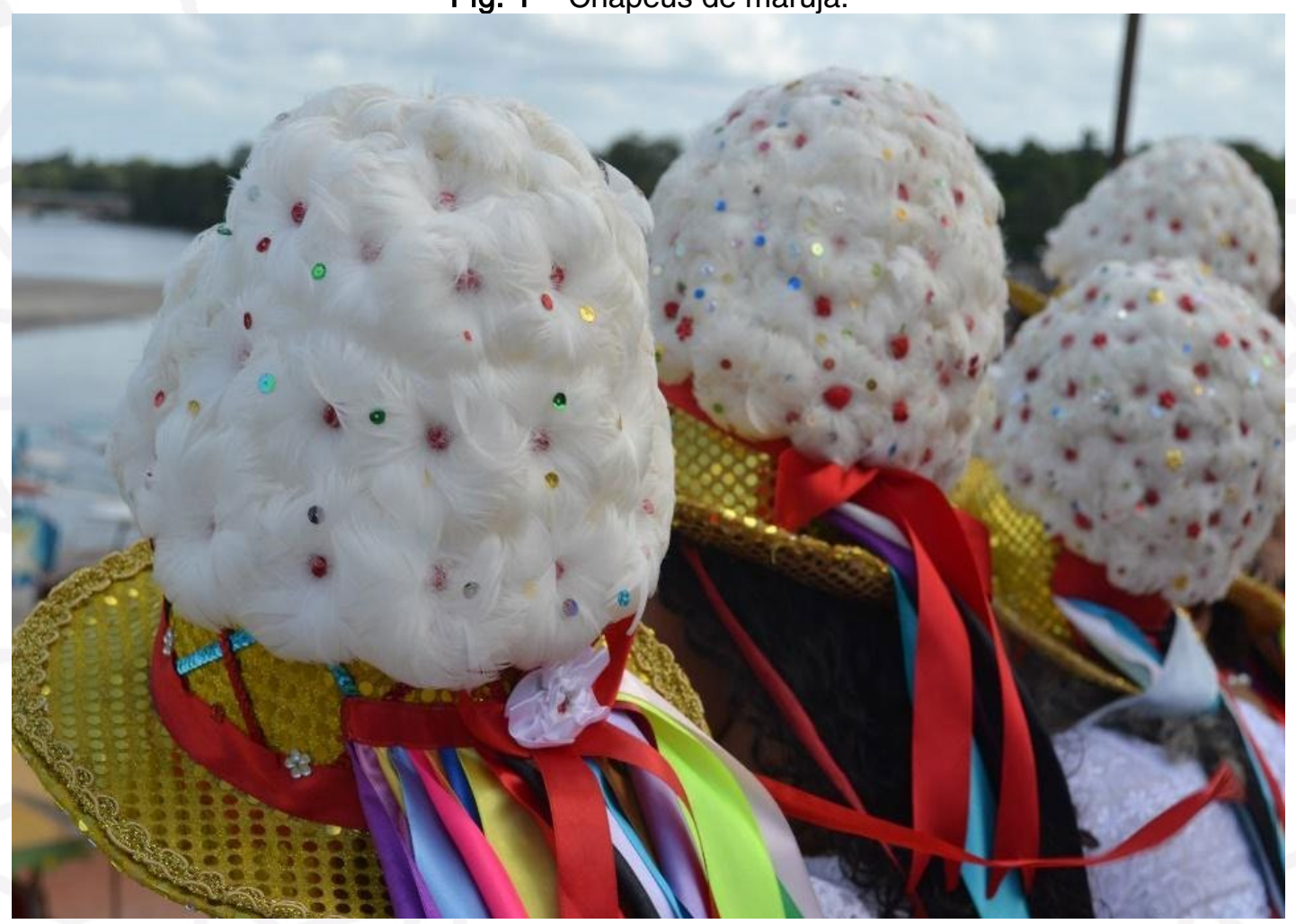

Fonte: Alexandre Baena

Fig. 2 - Chapéus de marujos.

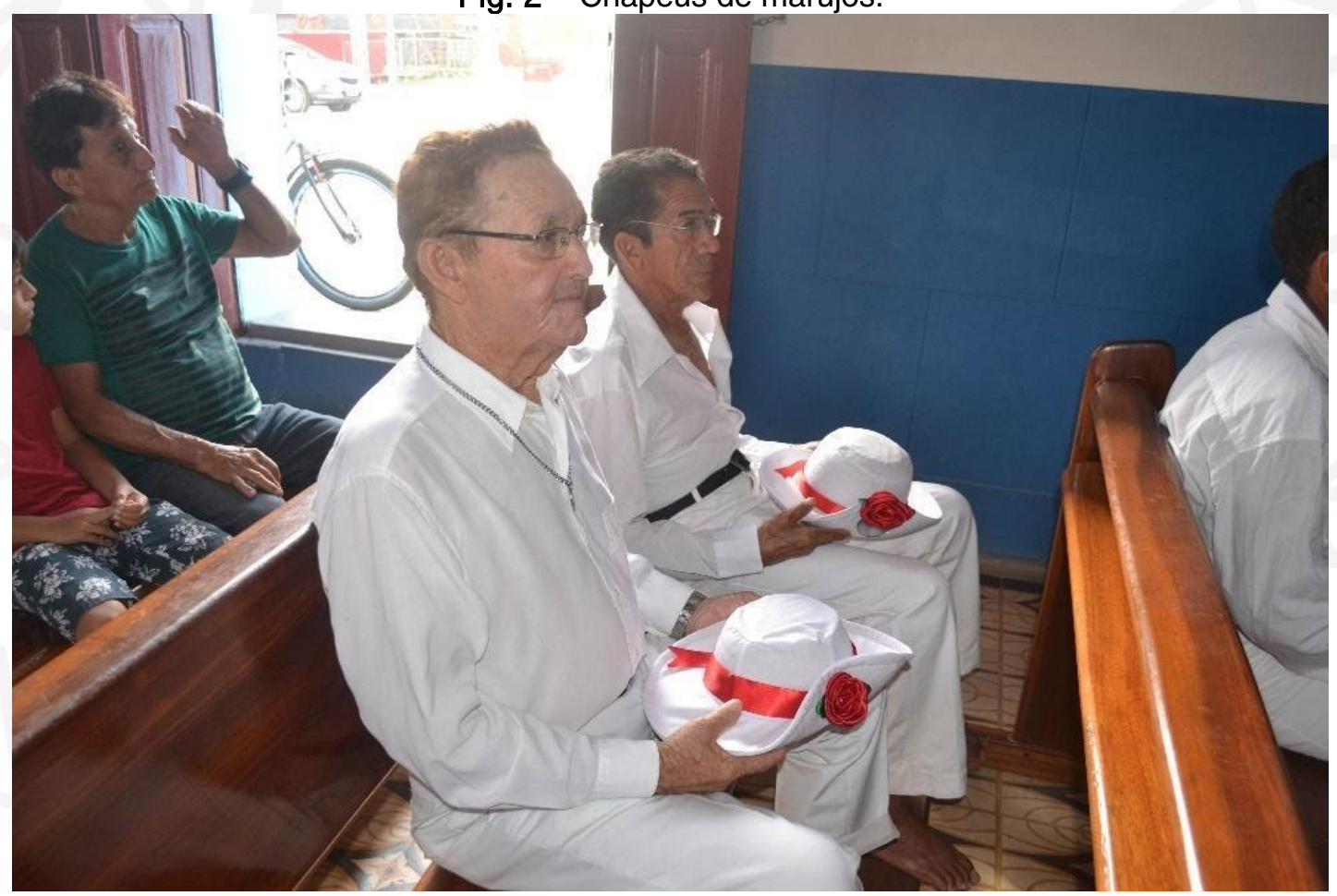

Fonte: Alexandre Baena 
Mediante a observação das imagens acima, demonstra-se que 0 modelo masculino possui uma forma modesta em comparação ao modelo feminino, que é considerado um dos objetos mais enigmáticos e provocantes no tocante à visualidade da devoção beneditina daquela localidade.

Um dos registros preliminares que reproduzem informações sobre este chapéu pode ser encontrado na obra "Contribuição ao estudo do folclore amazônico da zona bragantina", publicada em 1959 pelo pesquisador Armando Bordallo da Silva, reparemos como o autor reporta-se à forma e materiais diversos do que temos hoje nos chapéus contemporâneos.

As marujas se apresentam tipicamente vestidas. [...] na cabeça ostentam um chapéu todo emplumado e cheio de fitas multicores. [...] era antigamente feito de feltro, côco ou cartola. Os de fabríco moderno são de carnaúba, palhinha ou mesmo de papelão. Seja qual fôr o material empregado na estrutura básica do chapéu, êle é furado na parte interna e externa. A aba com papel prateado ou estanhado; lateralmente, com papel de côres; e em torno, formando um ou mais cordões em semicírculo, presos nas extremidades, em pontos equidistantes, são colocados voltas ou alças de casquilho dourado, prateado ou colorido. Entre as alças, por cima das voltas, são também colocados espelhinhos quadrados ou redondos. Ao alto plumas e penas de aves de diversas cores, formam um largo penacho com mais ou menos cincoenta centímetros de altura. Da aba, na parte posterior do chapéu, descem ao longo da costa da maruja, numerosas fitas multicores. O maior número ou largura das fitas, embora não indicando hierarquia, é reservado às mais antigas. (SILVA, 1959, p. 63)

A dimensão de materialidade, bem como a produção artesanal do referido objeto, tendo sido temas de estudo da pesquisadora Ana Mabell Seixas Alves Santos, são abordados pela autora sob diversos prismas. Em sua pesquisa de mestrado a autora ressaltou a escassez de informações anteriores aos anos 1950 sobre o chapéu. Nos registros imagéticos inseridos no documentário fotográfico do livro de Bordallo da Silva temos ainda uma figura que mostra o chapéu de uma das antigas Capitoas ${ }^{2}$. Verificamos, apesar da definição de imagem não fornecer nitidez, a opulência deste adereço na cabeça.

\footnotetext{
${ }^{2}$ Termo usado para se referir à líder das marujas de São Benedito.
} 
Por meio da exposição feita pelo autor, em conjunto com uma breve observação imagética concluímos que ocorreu uma significativa transformação no chapéu feminino ao longo do tempo.

Fig. 3 - Detalhes dos chapéus de marujas nos anos 50.

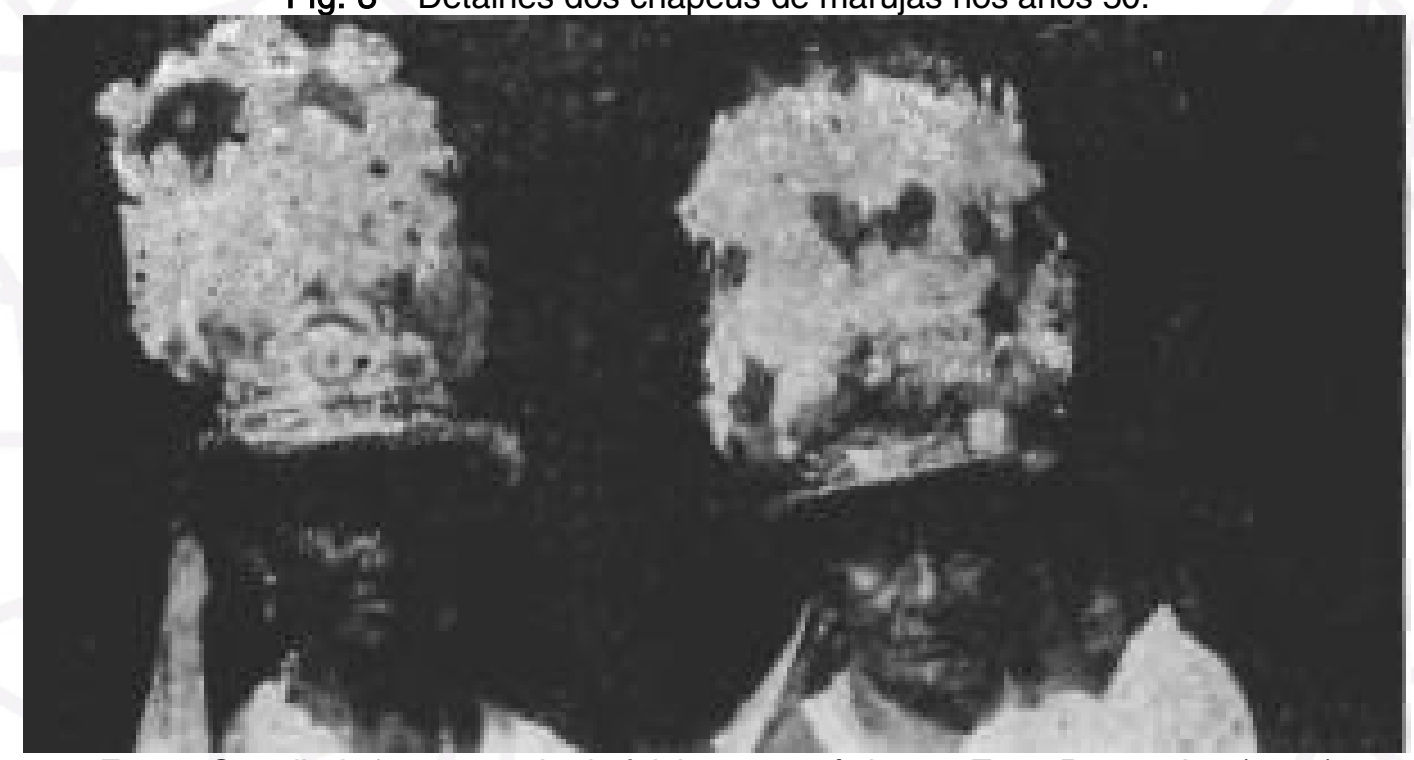

Fonte: Contribuição ao estudo do folclore amazônico na Zona Bragantina (1959)

Moraes, Aliverti e Silva tecem apontamentos sobre o chapéu moderno na obra "Tocando a memória da Rabeca", para os autores

\begin{abstract}
O chapéu é o item mais pomposo que compõe o figurino, e sua feitura envolve um longo processo artesanal. [...] Para sua confecção, um dos materiais principais são as penas de pato. [...] As penas são arranjadas de modo a formar pequenas flores brancas, que são presas por botões a uma armação que pode ser de palha, haste metálica, ou de isopor, esta torna o chapéu mais leve. A armação é recoberta por tecido, aumentando a altura da copa, enquanto a aba é recortada com tecido ou papel dourado. Completando sua ornamentação, amarra-se uma série de fitas de cetim das mais diversas cores, de um metro de comprimento que, durante os giros das marujas, parecem um arco-íris. (2006, p.69)
\end{abstract}

Com a exposição dos autores, depreende-se que as penas de pato passaram a ser predominantes. As flores que são confeccionadas com as penas, são presas em arames ou hastes de madeira, ou, ainda, em uma peça de isopor.

Não se sabe ao certo quando o suporte de isopor foi introduzido. Por meio dos depoimentos da artesã Teresa O'Grady é possível compreender melhor a feitura do adereço na atualidade, membro da Irmandade que 
organiza a festa e maruja ativa, ela é uma das artesãs de chapéu mais requisitadas em Bragança. A introdução do modelo de isopor, segundo ela, surgiu como uma alternativa mais durável para os chapéus de papel, que eram usados em tempos mais remotos. Sem lembrar com precisão das datas ela informou que:

Quem inventou este isopor foi uma menina lá na aldeia. ${ }^{3}$ Mas também a gente não aceitava mais o desconforto quando a gente saía com chapéu e como chegava. Tinha pessoas com condições pra mandar reformar e tinha pessoas que não, aí ficava com o chapéu muito feio. Aquele arame, se tu for te encostando numa pessoa, batendo, ele vai entrando e vai amassando, se virando, que quando tu olha ele não presta mais.

Além de fabricar chapéus, Teresa se interessa em rememorar dados do passado, empenhada em dominar a feitura com os materiais de hoje, mas também percebendo a importância de conhecer as origens do objeto que é sua especialidade. Mesmo com as progressivas transmutações sofridas, o caráter artesanal da fabricação dos chapéus é um processo reconhecidamente relevante. Ao buscar na memória suas visões sobre o adereço, a artesã resgata que:

Era pena de pássaros, pássaros, vários, entendeu? Não é o branco. O branco já é mais novo, assim foi mais pra próximo aqui digamos, se ela tem $218^{4}$ né? Vem vindo o que de uns 60,80 anos pra cá.

As variações de penas utilizadas na confecção dos antigos chapéus é um dado recorrente e mencionado por diversas fontes, orais e textuais. Em entrevista D. Bia, Capitoa ${ }^{5}$ atual da Marujada, declarou que a pena de galinha também fora bastante utilizada outrora, mas foi sendo substituída por não apresentar a curva necessária para a modelagem das pétalas da flor. Segundo Ana Mabell Santos:

Em geral, as penas que formam estas "flores" são retiradas do chamado pato nativo (Cairina moschata), mas há registros da utilização de outras aves, tais como garças (Ardea alba) e guarás

\footnotetext{
${ }^{3}$ Aldeia é um bairro do município de Bragança.

${ }^{4}$ Referente aos anos de existência da Irmandade e do culto ao santo na região.

${ }^{5}$ Concedida em novembro de 2019.
} 
(Eudocimus ruber), ou mesmo galinhas (Gallus gallus domesticus) (SANTOS, 2017, p. 41).

A adesão ao revestimento em tecido dourado é mais uma característica do chapéu contemporâneo. Vimos anteriormente, na citação da obra de Bordallo da Silva, que uma de suas versões, era coberto com papel metálico. A forma atual é um chapéu de palha que as artesãs revestem com algum tecido dourado sintético. São variadas também as texturas dos tecidos dourados, porém o mais presente é o que atende pelo nome comercial de "lantejoula".

Fig. 4 - Tecido dourado "lantejoula".

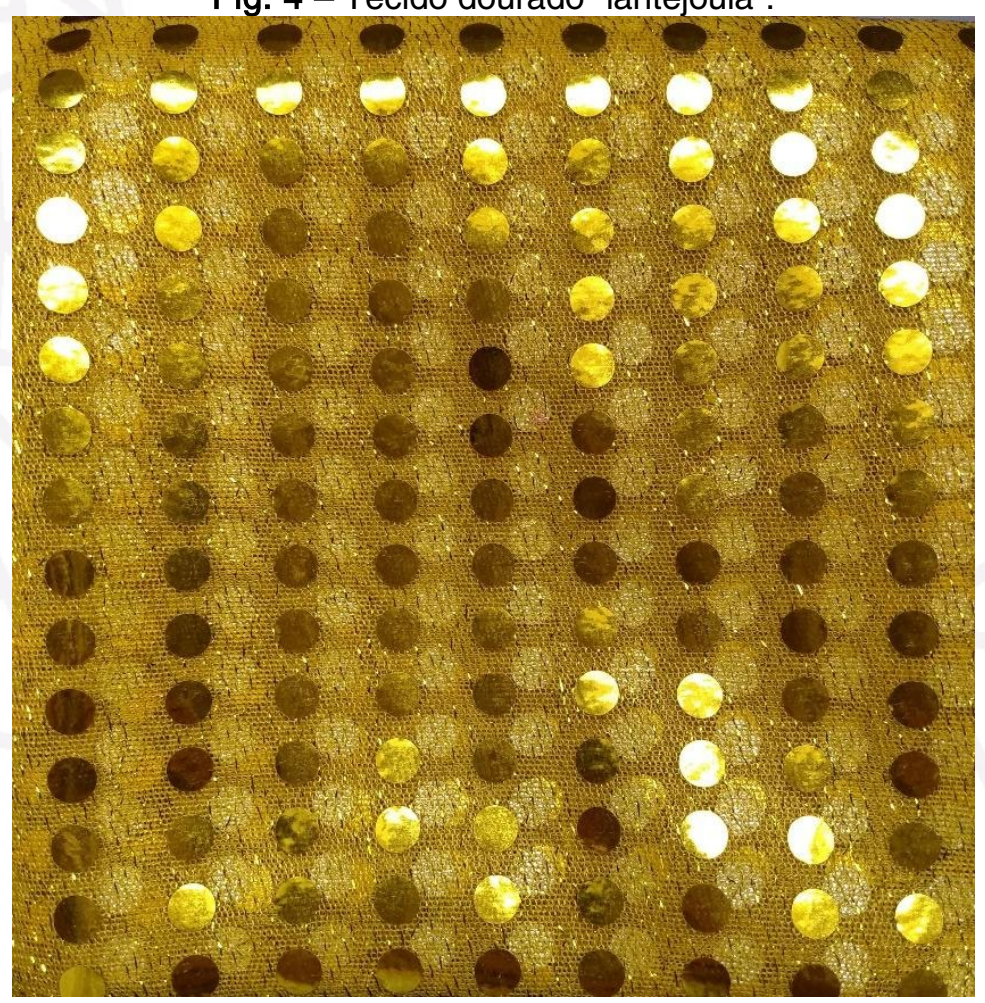

Fonte: Graziela Ribeiro

Ao comentar sobre a introdução de novos materiais, Teresa relatou que as novidades podem ser bem aceitas pelos membros, contanto que promovam algum benefício de ordem ergonômica e econômica, mas que não alterem a "tradição", ou seja, as inovações são principalmente nos materiais, que devem facilitar a vida dos usuários dos chapéus, pensando muito na durabilidade do objeto, mas mudanças bruscas na forma não são bem aceitas e configuram desrespeito à tradição. 
Para a decoração dos chapéus também são permitidos que sejam usadas miçangas, paetês, aviamentos, dourados e em vermelho são os preferidos e podem ser usados livremente de acordo com a criatividade das artesãs. Conforme afirma Santos:

Cada artesã possui uma visão peculiar do objeto que produz e reinventa a partir de seu repertório simbólico e imagético, sua habilidade técnica, seus valores e senso estético no que tange a materiais, cores, formas, volume e proporções. A transmissão deste saber artesanal, tal como ocorre nas narrativas africanas, ocorre por meio da tradição oral. (2017, p. 65)

O chapéu da maruja deve obrigatoriamente carregar também quatorze fitas coloridas na parte de trás, que provocam um efeito visual exuberante e intrigante, uma espécie de efeito arco-íris que gera muitos questionamentos a respeito da simbologia dessas cores.

Além das penas, os chapéus das marujas possuem longas fitas coloridas que, presas à base da copa do chapéu, descem às costas da mulher. O comprimento das fitas varia conforme a altura e o gosto pessoal da maruja, mas costuma ficar cerca de trinta centímetros acima dos pés. Assim como no tocante às penas, não há informações precisas sobre a origem ou o significado das fitas; também como ocorre com as penas, fitas são comuns a várias manifestações, desde as massificadas pelos meios de comunicação até outras, menos difundidas (SANTOS, 2017, p. 43).

Nos depoimentos coletados não foi mencionado nenhum sentido específico nas cores das fitas, apenas em relação ao número quatorze, pois representam os quatorze trabalhadores escravizados que deram início a esta devoção na região de Bragança, com o adendo que uma fita de cor preta deve ser afixada no centro das demais, pois ela homenageia as nações negras que historicamente iniciaram este culto. A resolução a respeito do número de fitas e da obrigatoriedade da fita preta foram introduzidas recentemente na indumentária das marujas, isso foi ressaltado por Teresa ao declarar que:

essa tem que ter, isso foi criação não é muito tempo não, porque a gente achava que o preto era feio né? Eu te digo porque no meu primeiro chapéu não existia, aí depois eles vieram que era pra gente 
botar o símbolo do chapéu, que era a fita preta né? A gente colocou e combinou.

No mito de origem do culto a São Benedito em Bragança consta que tudo se iniciou a partir de quatorze homens negros escravizados que viviam nas fazendas daquela região e que, em 1798, pediram autorização aos seus senhores para fundarem uma irmandade em louvor ao santo e construírem uma igreja. Em agradecimento, dançaram pela cidade, fato que anualmente passou a se repetir e reviver tal momento tão importante para aquela comunidade.

Com base nas clássicas fontes iconográficas que nos fornecem os arquétipos de personagens que vivenciaram a escravidão negra no Brasil nos séculos XVIII e XIX, como Carlos Juliao, Debret, Rugendas, Guilhobel, podemos perceber que a decoração na cabeça em festividades era uma prática comum. Portanto, acredita-se que no culto a São Benedito de Bragança não ocorreu de forma diferente. Plumas, fitas, turbantes, chapéus e outros adornos aplicados na "Or" (Cabeça) são ainda recorrentes nas celebrações afro religiosas no brasil. Santos, em sua pesquisa sobre o chapéu de Maruja, reconhece "a importância da cabeça nas expressões de religiosidade e nas culturas oriundas da África”. (2017, p. 38).

Nos resta tentar seguir os rastros destes adornos no sentido de desvendar possíveis simbologias que possam estar implícitas. No caso do chapéu de maruja, alguns elementos se mantém um mistério. Um deles é a utilização das penas das aves.

A pesquisadora Larissa Fontinele de Alencar em seu trabalho intitulado "No rastro dos pés descalços", que refletiu sobre o silenciamento das referências africanas na Marujada de Bragança, nos fornece o seguinte ponto de vista:

Seria ingenuidade pensar que ostentar as plumas brancas dos patos na cabeça, seja apenas uma ornamentação, um adereço, uma alegoria plástica. Afinal para se retirar as penas dos patos é necessário que eles morram antes, o que não significa que sejam utilizados em rituais, é apenas a constatação do símbolo revisitado. Afinal de contas, em algumas crenças galos, galinhas, patos e outras aves são sacrificadas em devoção às entidades, e por vezes, 
somente as penas ficam expostas nos altares do culto, como forma de referência ao rito. (ALENCAR, 2014, p.84)

Ana Mabell Santos resgata o sentido do termo "hibridismo" em uma das análises que faz do objeto em seu trabalho e alega que existem outras referências no uso das penas além dos adornos africanos, visto que supostamente a arte plumária também caracteriza os povos originários da região de Bragança, notadamente da nação Tupinambá, portanto para a autora "seria razoável supor que, em que pese a proclamada origem puramente africana do rito, é possível que tenha havido influência ameríndia na elaboração do chapéu da maruja”. (SANTOS, 2017, p. 42)

Em relação às fitas, sabemos que, além de desempenhar as funções de adorno ou para atar partes, houve também uma apropriação delas enquanto um forte elemento comunicacional dentro das festividades populares, visto que as fitas de cetim coloridas se tornaram uma estética recorrente em festividades brasileiras onde são vistas em chapéus, bastões, adereços e outros objetos, comuns em congadas, reisados, maracatu, folia de reis, sairé, marambiré, boi bumbá e a marujada bragantina.

Alguns estudos que investigam os sentidos das fitas do Senhor do Bonfim na Bahia apontam que as fitas coloridas, também chamadas "medidas" quando têm função de amuleto, associam as suas cores a entidades afro-religiosas, conforme vemos

\footnotetext{
Outras informações relacionam a sua variedade de cores ao sincretismo religioso brasileiro, muito influenciado pelas religiões africanas; nessa perspectiva, as cores correspondem às dos Orixás, que por sua vez, correspondem aos santos católicos. Não podemos esquecer da tradição popular católica, que ganha muitos matizes de cores, nas suas festas religiosas e nos seus folguedos, por exemplo, os reisados e as danças das fitas. (FERREIRA, 2005, s.p)
}

No verbete do Dicionário de Folclore de Câmara Cascudo, entende-se que a medida

É uma fita que representa o comprimento da imagem de santo. Estiram a fita da cabeça aos pés da imagem. É um amuleto, conforme o poder do santo, Medida de São Sebastião é para peste, feridas. De São Brás, para engasgos. De Santa Luzia para doenças 
dos olhos. De S. Onofre, contra a miséria. Do Senhor do Bonfim, contra as infelicidades. (CASCUDO, 2012, p. 446)

Embora as festividades mencionadas tenham uma origem popular, que predominantemente é composta pelas populações negras e caboclas desde o Brasil colonial até os dias de hoje, sabe-se que a estética das fitas de cetim coloridas, também são observadas em manifestações culturais de tradição ibérica luso-espanhola. Assim, é preciso compreender melhor de que forma as religiosidades de matriz africana também contribuem para essa estética. Nas festas ligadas ao catolicismo popular existem possibilidades destes elementos pertecerem à uma dimensão simbólica, que considera que as cores subliminarmente homenageiam Orixás que, a esta altura, foram sincretizados com santos da igreja católica. Com base nisso, há a possibilidade das fitas dos chapéus de marujas se relacionarem a entidades afro-religiosas.

Figuras 5 e 6: Chapéu de fitas da Marujada bragantina, 2017.

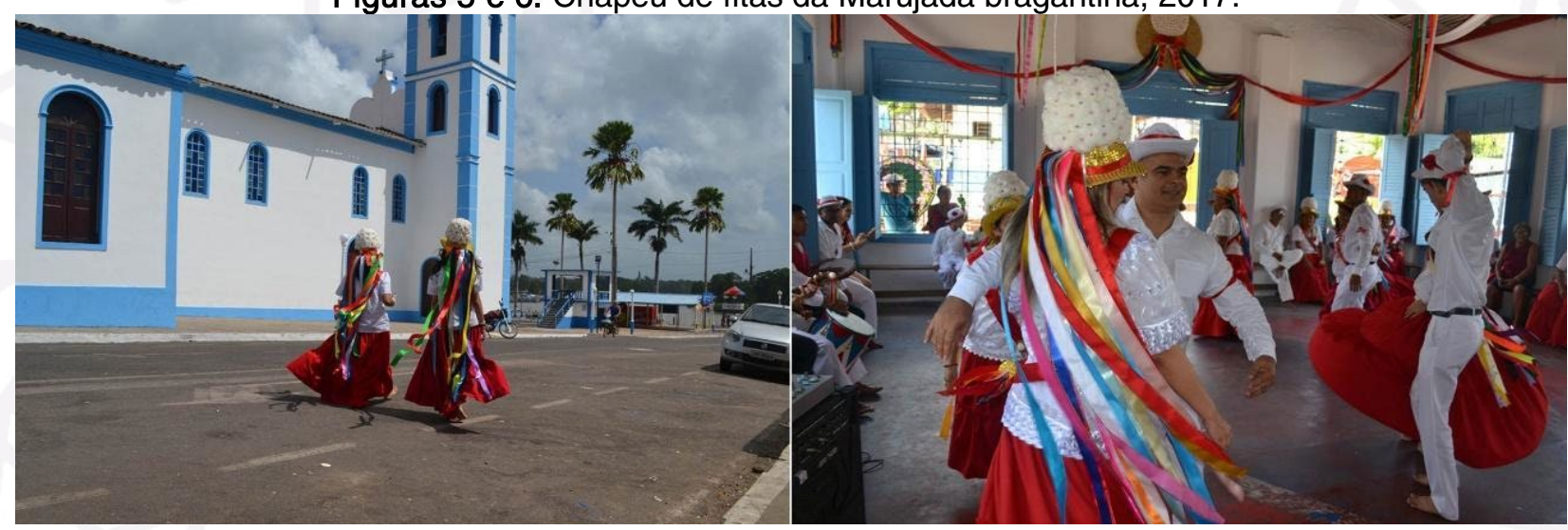

Apesar de ser um critério "obrigatório" a aplicação dessas quatorze fitas, no ponto de vista da artesã Teresa O'Grady a beleza do chapéu está na aplicação de um número maior de fitas. Ela informa que:

eu não concordo que eles querem só 14 fitas no chapéu, eu não concordo, porque 14 fitas no chapéu não é beleza entendeu? Quanto mais fita e colorido no teu chapéu é a coisa mais linda que fica, então eu não coloco, eu posso até dizer, agora fazer é outra coisa 
Antes de encerrar as reflexões acerca dos chapéus, cabe fazer um breve descritivo do chapéu dos Marujos para que fique perceptível além das imagens a discrepância que há entre o modelo masculino e o feminino. $O$ masculino é de palha simples, encapado por um tecido branco, com uma aba virada e presa à copa do chapéu. As fitas são apenas as azuis e as vermelhas, que acompanham a cronologia de uso das cores, dia 25 azul e 26 vermelha. Há também a aplicação discreta de flores de tecido na decoração lateral que fica dobrada. Em 2019, alguns Marujos voltaram a aplicar pequenos espelhos, na tentativa de resgatar a tradição antiga. Fato esse que não deve ser acompanhado nas próximas marujadas, visto que o ano citado foi o último da pesquisa de campo.

Conforme mencionado anteriormente, o modelo masculino é caracterizado pela modéstia, enquanto o feminino é opulento e materializa em um objeto um dado fundamental dentro da estrutura da devoção ao santo preto de Bragança: as mulheres que mandam. Levando em consideração tal fato, o chapéu de Maruja é comparado a coroas, primeiramente por Fernandes, ao afirmar que "Com indumentária com muitas fitas e brilhos, belo turbante que alude à coroa de realeza" (FERNANDES, 2011, p.730) e por Alencar, que enfatiza

O papel desempenhado pelo chapéu da maruja parece corresponder às descrições significativas de uma coroa, como se em si carregasse um signo da soberania, de autoridade e de poder, sobretudo com os espelhos, pedrarias e abas em cor de ouro. (2014, p.83)

Turbante, coroa, ameríndio, africano, ibérico. Podemos concluir que os chapéus da Marujada, além de intrigantes, despertam uma diversidade de teorias a respeito da sua origem, certamente tal objeto ainda pode render mais investigações futuras.

\section{Aspectos conclusivos}

Como conclusão, creio ser relevante destacar que é possível que reflexões teóricas profundas possam surgir a partir da atividade profissional 
prática, não apenas no campo do figurino, ou mesmo, no campo teatral, mas nas mais diversas dimensões e ambientes de trabalho.

A pesquisa teórica, embora tenha sido motivada pela atividade criativa, não teve como objetivo realizar um redesign do primeiro figurino. Também não teve a intenção de promover uma apropriação realista da textura das flores de pena de pato observadas nos chapéus das marujas, visto que um figurino teatral não precisaria retratar com fidelidade a textura verdadeira. $O$ figurinista é livre para deglutir informações do mundo real e devolver ao mundo de uma maneira criativa e inovadora.

Conforme se percebe na imagem abaixo, as penas de pato usadas no figurino mencionado, por serem sintéticas, não apresentam as mesmas formas das penas naturais de patos. Além disso, o botão do centro da flor, que na versão real são bolas de algodão revestidas com pedaço de fita de cetim vermelha e ganham o formato de centro de flor por meio da ação das aplicações das penas em sua volta, no figurino foram apenas pequenas sementes coladas com cola de isopor. Contemplando o que visualmente se percebe das flores de pena de pato de forma em uma linguagem estilizada.

Figuras 7: Penas sintéticas usadas no figurino de "Esse corpo que me veste", 2015.

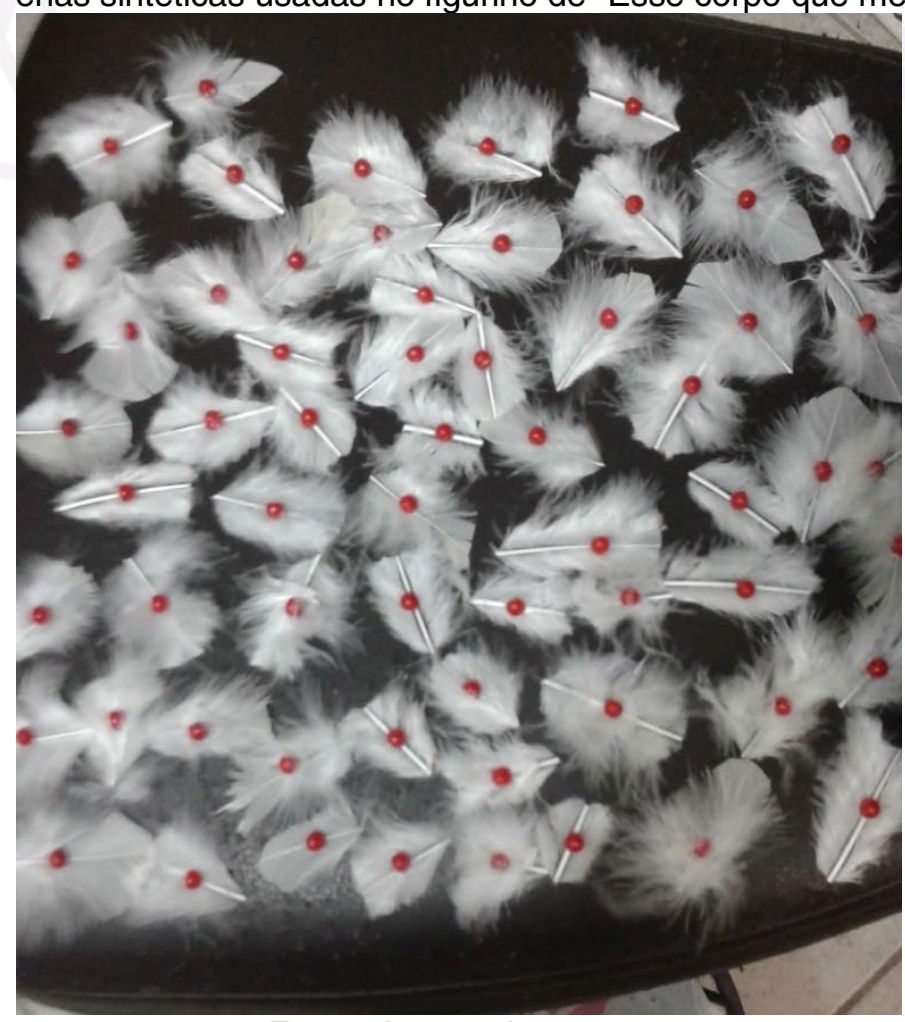

Fonte: Acervo da autora. 
Contudo, a pesquisa acadêmica proporcionou um aprofundamento acerca da pesquisa criativa e sobre modos de feitura das flores, além disso, resgatou as técnicas reais das artesãs, difundindo-as para as próximas gerações.

\section{Referências}

ALENCAR, Larissa Fontinele de. No Rastro dos Pés Descalços: Da marujada à narrativa literária. Dissertação de mestrado apresentada ao programa de PósGraduação em Linguagens e Saberes na Amazônia. Bragança, 2014.

CASCUDO, Luis da Câmara. Dicionário do Folclore Brasileiro. São Paulo:

Melhoramentos, 2012.

COULON, 1995. A Etnometodologia. Petrópolis: Vozes, 1995.

FERNANDES, José Guilherme. Pés que andam, pés que dançam: memória, identidade e região cultural na esmolação e marujada de São Benedito em Bragança, PA. Belém: EDUEPA, 2011.

FERREIRA, A. D. A. Trocando em miúdos a "medida do Bonfim". Salvador: Anais do I Enecult, 2005.

GARFINKEL, Harold. Estudos de Etnometodologia. Petrópolis: Vozes, 2018. MORAES, José P. da C.; ALIVERTI, Mavilda J.; SILVA, Rosa M. M. da. Tocando a memória. Rabeca. Belém: IAP, 2006.

SANTOS, Ana M. S. A. Mãos, Penas e Fitas: O chapéu da maruja como cultura material em Bragança-PA. Dissertação de Mestrado- Universidade Federal do Pará, Programa de Pós Graduação em Linguagens e Saberes na Amazônia da. Bragança, 2017

SILVA, Armando Bordallo da. Contribuição ao Estudo do Folclore Amazônico na Zona Bragantina. Belém: Falangola, 1981.

WEBSITE JORNAL DIÁRIO DO PARÁ ON-LINE. Link:

https://www.diarioonline.com.br/_noticia-352952-grupo-cuira-encena-novoespetaculo-em-casa-nova.html WEBSITE FUNDAÇÃO CULTURAL DO PARÁ. Link: http://fcp.pa.gov.br/noticias/1489-esse-corpo-que-me-veste-sera-exibido-nestasegunda-feira-no-cine-alexandrino-moreira WATSON, Rod; GASTALDO, Édison. Etnometodologia \& Análise de conversação. Petrópolis, RJ: Vozes; Rio de Janeiro: Editora PUC-Rio, 2015. 